\title{
Article \\ Chondroitin Sulfate Disaccharides, a Serum Marker for Primary Serous Epithelial Ovarian Cancer
}

\author{
Karina Biskup $^{1}$, Caroline Stellmach ${ }^{1}$ (D), Elena Ioana Braicu ${ }^{2}$, Jalid Sehouli ${ }^{2}$ and Véronique Blanchard ${ }^{1, *(D)}$ \\ 1 Institute of Laboratory Medicine, Clinical Chemistry and Pathobiochemistry, Charité-Universitätsmedizin \\ Berlin, Corporate Member of Freie Universität Berlin, Humboldt-Universität zu Berlin, and Berlin Institute of \\ Health, 13353 Berlin, Germany; karina.biskup@charite.de (K.B.); caroline.stellmach@charite.de (C.S.) \\ 2 European Competence Center for Ovarian Cancer, Department of Gynecology, Berlin Institute of Health, \\ Charité-Universitätsmedizin Berlin, Corporate Member of Freie Universität Berlin, Humboldt-Universität zu \\ Berlin, 13353 Berlin, Germany; elena.braicu@charite.de (E.I.B.); jalid.sehouli@charite.de (J.S.) \\ * Correspondence: veronique.blanchard@charite.de
}

Citation: Biskup, K.; Stellmach, C.; Braicu, E.I.; Sehouli, J.; Blanchard, V. Chondroitin Sulfate Disaccharides, a Serum Marker for Primary Serous Epithelial Ovarian Cancer. Diagnostics 2021, 11, 1143. https://doi.org/ 10.3390/diagnostics11071143

Academic Editor: Jill Marie Kolesar

Received: 3 June 2021

Accepted: 21 June 2021

Published: 23 June 2021

Publisher's Note: MDPI stays neutral with regard to jurisdictional claims in published maps and institutional affiliations.

Copyright: (c) 2021 by the authors. Licensee MDPI, Basel, Switzerland. This article is an open access article distributed under the terms and conditions of the Creative Commons Attribution (CC BY) license (https:/ / creativecommons.org/licenses/by/ $4.0 /)$.

\begin{abstract}
Glycosaminoglycans are long polysaccharidic chains, which are mostly present in connective tissues. Modified GAG expression in tissues surrounding malignant cells has been shown to contribute to tumor progression, aggressive status and metastasis in many types of cancer. Ovarian cancer is one of the most lethal gynecological malignancies due to its late diagnosis because of the absence of clear symptoms and unavailability of early disease markers. We investigated for the first time GAG changes at the molecular level as a novel biomarker for primary epithelial ovarian cancer. To this end, serum of a cohort of 68 samples was digested with chondroitinase ABC, which releases chondroitin sulfate into disaccharides. After labeling and purification, they were measured by HPLC, yielding a profile of eight disaccharides. We proposed a novel GAG-based score named "CS- bio" from the measured abundance of disaccharides present that were of statistical relevance. CS-bio's performance was compared with CA125, the clinically used serum tumor marker in routine diagnostics. CS-bio had a better sensitivity and specificity than CA125. It was more apt in differentiating early-stage patients from healthy controls, which is of high interest for oncologists.
\end{abstract}

Keywords: chondroitin sulfate; disaccharide; glycosaminoglycan; ovarian cancer; biomarker; HPLC

\section{Introduction}

Although surgical techniques and therapies have improved in the past years, ovarian cancer (OC), one of the rarer gynecological carcinoma types, remains the most lethal gynecological malignancy [1]. The reason for the high mortality rate is that the disease remains clinically silent in the early stages and tends to be diagnosed only when the late stages are reached [2]. Hence, only $10-20 \%$ of patients are diagnosed in the early stages (stage I: localized in the ovary, stage II: localized in the pelvis) whereas approx. 80\% of patients are diagnosed at a late stage of the disease (stages III and IV) [3,4]. For decades, the standard of care has been debulking surgery followed by platinum- or taxane-based chemotherapy. Prognosis directly correlates with the presence and size of residual tumors remaining after surgery. Indeed, most patients initially respond to chemotherapy but will become chemo-resistant upon relapse [5]. As a result, insufficient screening methods and late-stage detection are the primary causes of poor prognosis. OC is diagnosed using pelvic examination and transvaginal ultrasound in combination with the measurement of the serum levels of Carbohydrate Antigen 125 (CA125). Regarding primary diagnosis, CA125 alone has a low sensitivity of $57 \%$, especially in early stages of OC and a specificity of 97\% [6]. The other routine biomarker available is Human Epididymis 4 (HE4). It shows slightly better performance than CA125 in pre-menopausal women but has otherwise low sensitivity [7]. Modeling simulations estimated that early diagnosis could not only improve survival by $10-30 \%$ but also be cost-effective [8]. 
As glycosylation is modulated at the onset and the course of cancer, it is an interesting source of biomarkers [9-12]. Glycosaminoglycans (GAG) are glycoconjugates, which are mostly present in connective tissues. They are found either in free form or as constituents of proteoglycans in the extracellular matrix [13]. Being composed of long polysaccharidic chains, GAG are key components of the extracellular matrix in healthy connective tissues and play an important role in homeostasis, regulation of cell growth, angiogenesis, migration, recognition and disease [14]. Due to their structural diversity, GAG actively take part in cellular events by binding a wide range of different molecules (for instance growth factors, cytokines, chemokines, enzymes) at the surface of cells and tissues. As a consequence, GAG promote inflammation that accompanies many types of inherited and acquired diseases. GAG modulations are observed during the development of many diseases (cancer, neuroinflammation, atherosclerosis, diabetes) within tissues and, as a result, in blood that is in circulation $[15,16]$.

Biological processing of glycoconjugates unlike proteins is not template-driven and results from the availability of activated monosaccharides, glycosidases, glycosyltransferases, sulfotransferases and epimerases. GAG are negatively charged linear polysaccharide chains that are built of disaccharide repeating units. This study concentrates on the analysis of non-sulfated hyaluronic acid (HA) - consisting of $\beta(1-3)$-GlcNAc $\beta(1-4)$-GlcA-as well as chondroitin sulfate (CS) — consisting of $\beta(1-3)$-GalNAc $\beta(1-4)$-GlcA. CS-0S denotes a non-sulfated disaccharide. CS sulfation can occur at the $\mathrm{C} 2$ position of glucuronic acid (GlcA), (named CS-2S) and the C4 and C6 position of $\mathrm{N}$-acetylgalactosamine (GalNAc), named CS-4S or CS-6S. Combinations of these sulfation patterns are possible, resulting in the disaccharides CS-2S4S, CS-2S6S, CS-4S6S, CS-2S4S6S.

Modified GAG expression in tissues surrounding malignant cells has been shown to contribute to tumor progression, aggressive status and metastasis for many types of cancer, namely ovarian cancer [17], breast cancer [18], colorectal cancer [19], hepatocellular carcinoma [20], renal cell carcinoma [21], pancreatic cancer [22], and gastric carcinoma [23]. In addition, elevated levels of chondroitin synthase I and III, which synthesize CS chains, were measured in various types of cancer [24-27]. CS chains interact with growth factors or are stored in the extracellular matrix and released gradually within the matrix, promoting cell signaling [16]. In other words, CS overexpression as well as modulated sulfation are hallmarks of cancer development [28,29]. Moreover, CS-proteoglycan expression has been shown to correlate with both tumor differentiation and prognosis [30]. In this work, we investigated for the first time GAG changes at the molecular level as a novel biomarker for primary epithelial ovarian cancer.

\section{Materials and Methods}

All chemicals were purchased from Sigma-Aldrich (St. Louis, MO) unless stated otherwise. MilliQ water was used from a MilliQ Plus Millipore system (Darmstadt, Germany).

\subsection{Patient Samples}

Primary ovarian serum samples were obtained from the Tumor Bank Ovarian Cancer project (http: / / www.toc-network.de/) of the Charité Medical University (Berlin, Germany). The Ethics Committee approved the use of the samples (EA4/073/06). The patient's informed consent was obtained prior to surgery or during subsequent treatment. Blood samples were collected prior to surgery. The tumor pattern was intraoperatively prospectively assessed based on the surgical procedures performed, through a systematic interview of the surgical team and by histology. All findings and associated data were registered in a validated documentation system specifically developed for ovarian neoplasms [31-35]. The menopausal status was not provided. Enrolled patients did not suffer from any other forms of cancer. Sepsis samples were obtained as approved by the ethical approval (EA1/285/09) of the Charité Medical University (Berlin, Germany).

In this study, 28 primary serous patients (FIGO: stage $1, n=13$; stage 2, $n=5$; stage 3 , $n=5$; stage $4, n=3$; not defined, $n=2$ ), 10 patients suffering from sepsis and 30 age- 
matched healthy controls were enrolled ( 5 patients suffering from benign ovarian diseases and 25 healthy controls). Patient's data are presented in Table 1. Blood was collected using serum tubes containing clotting activators (Vacutainer, BD, Medical-Pharmaceutical System, Franklin Lakes, NJ, USA). Collected blood was left to clot at room temperature for $30 \mathrm{~min}$ to $2 \mathrm{~h}$, then serum was separated by centrifugation at $1200 \mathrm{~g}$ for $15 \mathrm{~min}$. Serum was aliquoted and stored at $-80^{\circ} \mathrm{C}$ until the time of analysis.

Table 1. Demographics of the cohorts used in this study.

\begin{tabular}{lccc}
\hline & & Control & EOC \\
\hline No of Patients & & 30 & 28 \\
\hline Age & & & \\
& mean & 52.6 & 60 \\
& median & 50.5 & 59.5 \\
stage & SD & $17-81$ & $35-79$ \\
& I & 13.1 & 10.9 \\
& II & & 13 \\
& III & & 5 \\
CA125 in kU/L & IV & & 5 \\
& n.d. & & 3 \\
& mean & & 2 \\
& median & & 218.5 \\
& range & 36.8 & 62 \\
& SD & 15 & $10-1504$ \\
& & $6-386$ & 388 \\
\hline
\end{tabular}

\subsection{Protein Release}

An amount of $50 \mu \mathrm{L}$ pronase $\mathrm{E}(20 \mathrm{mg} / \mathrm{mL})$ dissolved in $20 \mathrm{mM} \mathrm{CaCl}_{2}$ was added to $50 \mu \mathrm{L}$ serum aliquots. After adding $150 \mu \mathrm{L}$ milli-Q water, samples were incubated at $55^{\circ} \mathrm{C}$ overnight to achieve protein digestion. On the following day, the reaction was stopped by heating the samples at $95^{\circ} \mathrm{C}$ for $10 \mathrm{~min}$. After cooling down, samples were centrifuged at $10,000 \times g$ for $10 \mathrm{~min}$ at $4{ }^{\circ} \mathrm{C}$. Supernatants were applied to $3 \mathrm{kDa}$ Amicon columns.

\subsection{Release of Disaccharide GAG}

Amounts of $5 \mu \mathrm{L}$ Chondroitinase $\mathrm{ABC}$ from Proteus vulgaris $(10 \mathrm{mU} / \mu \mathrm{L}$ dissolved in $0.01 \%$ (wt/vol) BSA) and $200 \mu \mathrm{L}$ of $200 \mathrm{mM} \mathrm{NaOAc}, 8 \mathrm{mM} \mathrm{CaCl}_{2} \mathrm{pH} 7.5$ were added to the retentates and the total volume was brought to $800 \mu \mathrm{L}$ with milli-Q water. Samples were incubated overnight at $37^{\circ} \mathrm{C}$ at $150 \mathrm{rpm}$. The following day, they were desalted using $3 \mathrm{kDa}$ Amicon filters following the manufacturer's instructions. Chondroitinase $\mathrm{ABC}$ degrades CS via B-elimination of internal GlcA residues, yielding an unsaturation denoted $\Delta$.

\subsection{2-AB-Labeling and Purification}

Dried GAGs were dissolved in $25 \mu \mathrm{L} \mathrm{10 \%}$ acetic acid/milli-Q water solution. They were then mixed with $25 \mu \mathrm{L}$ labeling solution consisting of $1 \mathrm{M}$ 2-aminobenzamide (2$\mathrm{AB}$ ) and $0.24 \mathrm{M}$ 2-picoline-borane in $10 \%$ acetic acid/MeOH. The reaction mixture was incubated in a Thermomixer for $3 \mathrm{~h}$ at $50{ }^{\circ} \mathrm{C}$, shaken at $500 \mathrm{rpm}$ in the dark. The reaction was stopped by the addition of $50 \mu \mathrm{L}$ of milli-Q water.

\subsection{Purification of 2-AB-Disaccharides Using G10 Columns}

PD MiniTrap G10 columns (GE Healthcare, Solingen, Germany) were equilibrated with 6 column volumes of milli-Q water. Labeled samples, brought to a volume of $100 \mu \mathrm{L}$ using Milli-Q water, were loaded onto the columns, which were subsequently washed with $550 \mu \mathrm{L}$ milli-Q water. Samples were eluted with $1250 \mu \mathrm{L}$ milli-Q water and dried under vacuum. 


\subsection{HPLC Measurements}

The 2-AB-labeled GAG disaccharides were dissolved in $90 \%$ ACN then measured by HPLC (Dionex, Idstein, Germany) using a SeQuant ZIC-HILIC column (Merck Millipore, Germany) and detected by fluorescence $\left(\lambda_{\text {excitation }}=330 \mathrm{~nm}\right.$ and $\left.\lambda_{\text {emission }}=420 \mathrm{~nm}\right)$. Separations were performed at $25{ }^{\circ} \mathrm{C}$ with a gradient elution at a flow rate of $200 \mu \mathrm{L} / \mathrm{min}$ for 95 min using $\mathrm{H}_{2} \mathrm{O}$ (solvent $\mathrm{A}$ ), acetonitrile (ACN, solvent $\mathrm{B}$ ) and $200 \mathrm{mM}$ ammonium acetate buffer $\left(\mathrm{NH}_{4} \mathrm{OAc}\right.$, solvent $\left.\mathrm{C}\right)$. The applied gradient was initiated with $5 \%$ A, $90 \%$ B, 5\% C then was increased in $60 \mathrm{~min}$ to $30 \%$ A, 65\% B, 5\% C. Peaks were assigned by comparison with a standard mixture of the following 9 disaccharide standards: $\triangle$ HexA( $\beta 1-3)$ GlcNAc (HA-0S), $\triangle$ HexA( $\beta 1-3)$ GalNAc (CS-0S), $\triangle$ HexA2S( $\beta 1-3)$ GalNAc (CS2S (Dextra, Reading, UK)), $\triangle$ HexA( $\beta 1-3)$ GalNAc4S (CS-4S), $\triangle$ HexA( $\beta 1-3)$ GalNAc6S (CS-6S (Dextra, Reading, UK)), $\triangle$ HexA2S( $\beta 1-3)$ GalNAc6S (CS-2S6S (Dextra, UK)), $\triangle$ HexA2S( $\beta 1-$ 3)GalNAc4S (CS-2S4S (Dextra, UK)), $\triangle$ HexA( $\beta 1-3)$ GalNAc4S6S (CS-4S6S (Dextra, Reading, UK)), $\triangle$ HexA2S( $\beta 1-3)$ GalNAc4S6S (CS-2S4S6S (Dextra, Reading, UK)). Relative quantification was conducted using the open source OPENchrom software Community Edition 1.3.0. (Hamburg, Germany).

\subsection{Statistical Analysis}

Statistical analysis was performed using SPSS version 25.0 (SPSS Inc., Chicago, IL, USA).

\section{Results}

We analyzed the serum CS- content of 28 primary ovarian cancer patients, 10 sepsis patients and 30 age-matched healthy volunteers. To do so, the protein moiety of proteoglycans was first cleaved using pronase, a cocktail of proteases. After purification, the resulting glycosaminoglycan samples were digested with chondroitinase ABC yielding CS disaccharides as well as the hyaluronic acid disaccharide (HA). They were subsequently labeled with 2-AB, a neutral fluorescent label, then measured by HPLC using a HILIC column. Representative spectra are presented in Supplementary Figure S1. Repeatability of HPLC measurements and of sample preparation is presented in Supplementary Tables S1 and S2, respectively. The one-sample Shapiro-Wilk test was carried out to assess the distribution normality in each group (healthy controls, early stage = FIGO I and FIGO II, late stage $=$ FIGO III + FIGO IV). It showed that the data was not normally distributed and therefore non-parametric tests were used for further statistical evaluation. Bar charts were generated to visualize the distribution of relative areas of single GAG-structures between EOC serum and the healthy control group (Figure 1). Error bars are shown as standard errors [36]. A Mann-Whitney U-test was performed to assess the statistical significance between EOC patients and controls. $p$-Values smaller than 0.05 were considered to be statistically significant. CS-0S and CS-4S are the two most abundant structures and constitute the majority of the CS disaccharide pool (Figure 1a). The six disaccharides HA-0S, CS-2S, CS-6S, CS-2S6S, CS-2S4S and CS-4S6S were detected in small amounts but the trisulfated disaccharide CS-2S4S6S was not present in serum samples.

Statistically significant increases of the monosulfated CS-2S, CS-4S and the disulfated CS-2S4S were observed accompanied by statistically significant decreases of the nonsulfated CS-0S and the disulfated CS-4S6S (Figure 1b). Heparin and heparan sulfate from human serum were also isolated and then further digested with a combination of heparinase I, II and III but no statistically significant changes between EOC patients and controls were observed (data not shown). In order to address whether the observed changes of CS-disaccharides in EOC patients were related to the inflammation that accompanies cancer development, we added a cohort of 10 patients suffering from sepsis Supplementary (Figure S2) to this work. The CS-disaccharidic profile of sepsis patients is very different from the profile of EOC patients. 

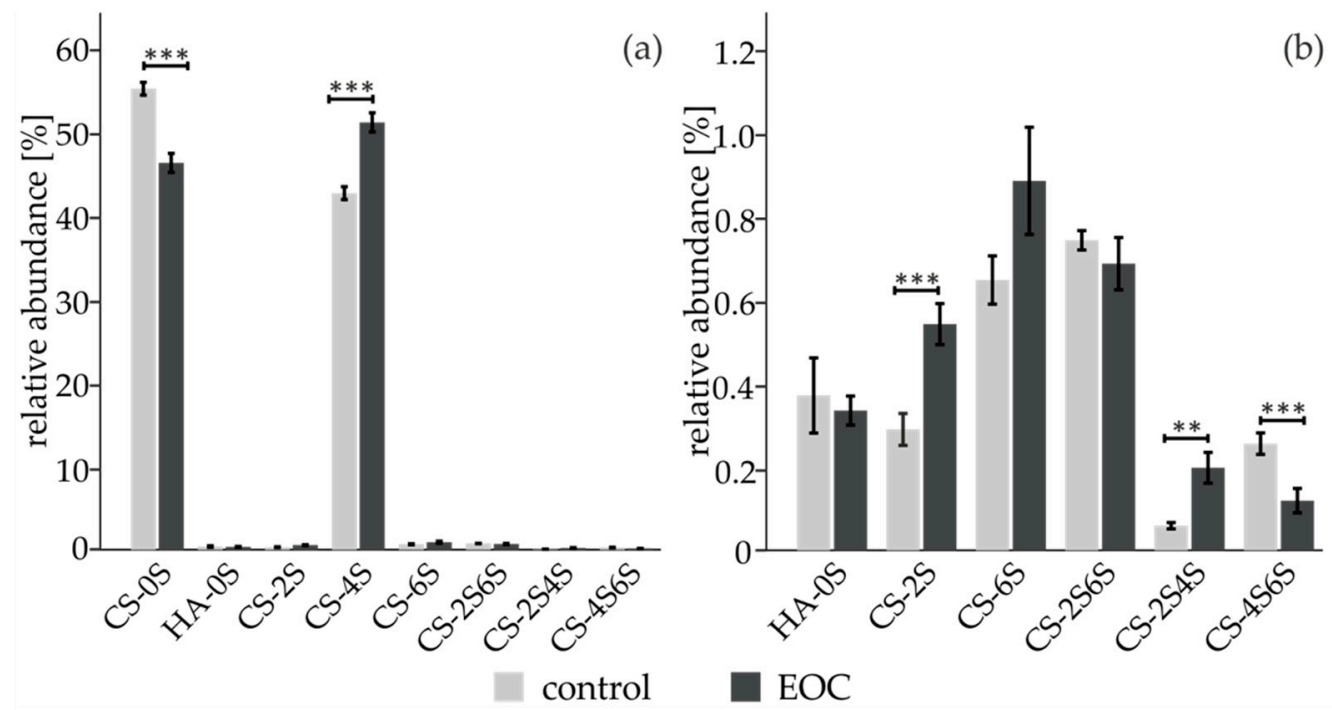

Figure 1. (a) Mean and 95\% confidence intervals [1] of relative areas of CS disaccharides released from human serum measured by HPLC coupled to fluorescence detection. (b) Enlarged view of the low abundant CS disaccharides. ${ }^{*} p<0.5,{ }^{* *} p<0.01,{ }^{* * *} p<0.001$ as judged from non-parametric Mann-Whitney U-test. S indicates sulfate and the preceding digit indicates the sulfation position.

Thereafter, receiver operating characteristic (ROC) curves were built for the CS disaccharides that were of statistical relevance (Figure S3). The greatest areas under the curve (AUC) were obtained for CS-0S (0.81), CS-2S (0.88), CS-4S (0.74) and CS-2S4S (0.91). Next, we tested which combinations of these CS disaccharides could improve ovarian cancer diagnostics using binary logistic regression. The following prediction model, named "CS-bio", was built: $27.974-0.642 \times$ CS-0S + 4.633 $\times$ CS-2S + 27,205 $\times$ CS-2S4S. The logistic regression model showed statistical significance $\left[\chi^{2}{ }_{(3)}=60.301, p<0.001\right]$, as it explained $86.2 \%$ (Nagelkerke $\mathrm{R}^{2}$ ) of the variance in ovarian cancer.

Few publications have addressed age-dependency of circulating GAG. Hence, we investigated whether a correlation could be established between the CS-disaccharide species that make up the CS-bio marker and the age of ovarian cancer patients and healthy controls using a linear regression model. Linear graphs with the best fitting regression lines are illustrated with a scatter point diagram (Figure S4). In addition, coefficients of determination $\left(R^{2}\right), \beta$ regression coefficients and $p$-values were calculated. We found an absence of correlation between age and abundance of CS disaccharides (Figure S4). Therefore, we concluded that presence of CS-0S, CS-2S and CS-2S4S was independent of the age of patients and controls.

Binary logistic regression was carried out to further evaluate the ability of the diagnostic GAG-based marker to correctly classify the cohort of patients. The diagnostic accuracy of CA125 and CS-bio was assessed by building the ROC curve at 95\% confidence interval (CI) and calculating the AUC. CS-bio had an AUC of 0.98, which was superior to CA125 (0.87) for both the whole cohort of patients and early-stage patients only (AUC: 0.87 (Figure 2a) and 0.81 (Figure 2b), respectively). Overall, CS-bio had a better sensitivity $(100 \%)$ and specificity $(93 \%)$ than CA125 (60\% and $83 \%$ respectively).

Box plots were generated to examine the subcategories of patients (Figure 3). All box plots were created after logarithmic transformation of CA125 values, which reduces skewness in the distribution of the results. Independent variables consisted of four ordinal groups of cancer progression (healthy controls, FIGO I, FIGO II and late stage = FIGO III + FIGO IV), while dependent variables were measured on a continuous level. A nonparametric multiple comparison Jonckheere-Terpstra test $\left(\mathrm{T}_{\mathrm{JT}}\right)$ was carried out to test the significance during cancer progression. $p$-Values were calculated after Bonferroni correction and are presented on Figure 3. Both CS-bio and CA-125 were able to discriminate between healthy controls and EOC patients (Figure 3a,b). Interestingly, CS-bio was statistically 
upregulated in early-stage patients (FIGO I) whereas CA125 was not (Figure 3c,d).
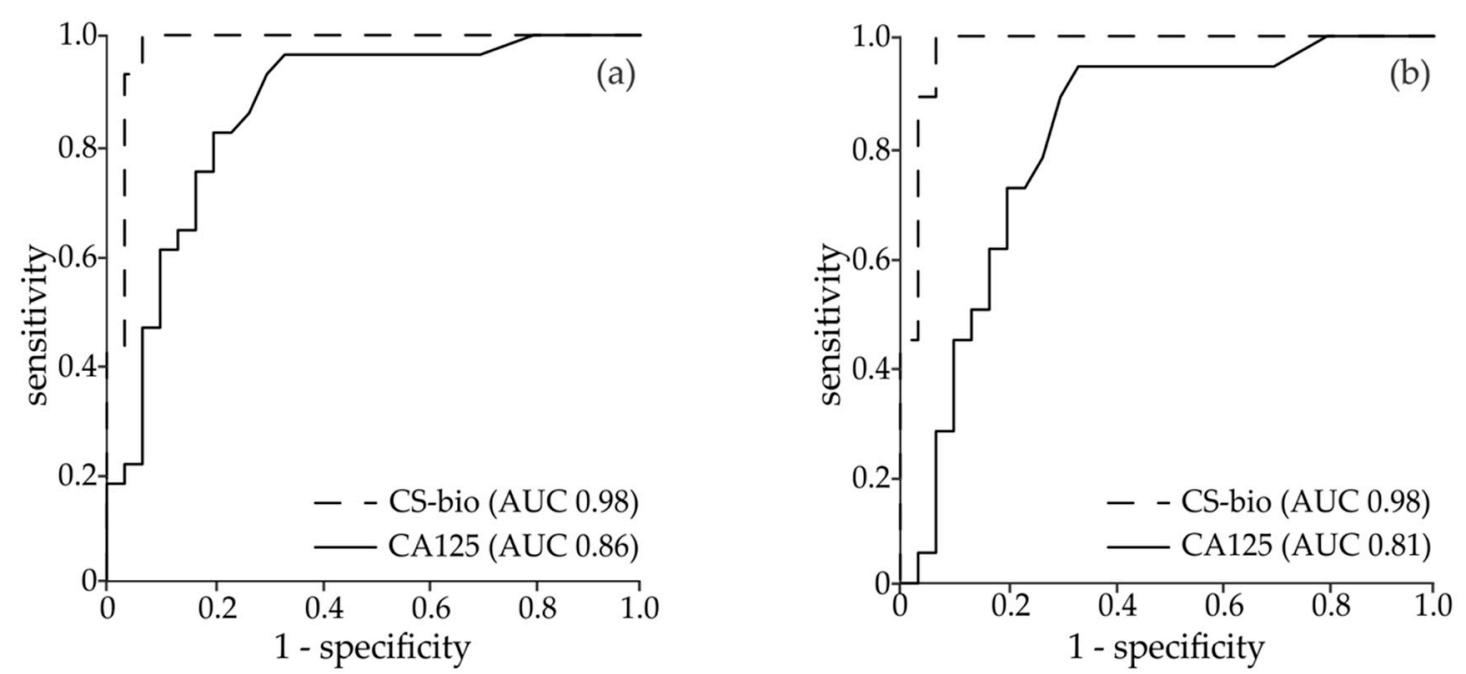

Figure 2. ROC curves of the biomarkers CS-bio and CA125 for (a) all EOC $(n=26)$ and control samples included in this study $(n=30)$ and $(\mathbf{b})$ early stage (FIGO I + II, $n=18)$ and control samples $(n=30)$.
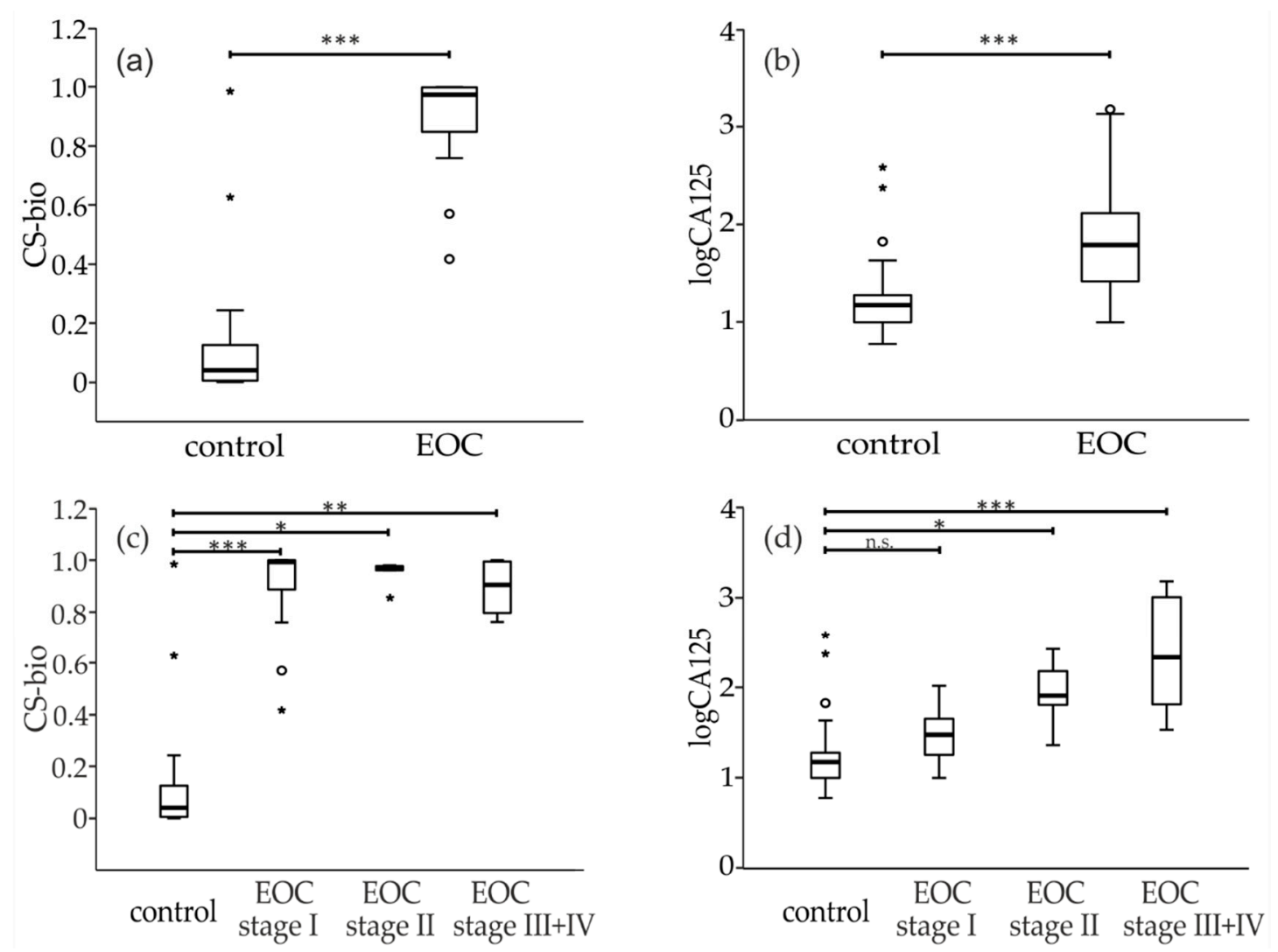

Figure 3. Boxplots were performed for CS-bio and logarithmic values of CA125. In (a,b), the whole cohort was considered in the EOC group. In (c,d), the EOC cohort was divided according to stages. The Bonferroni corrected $p$-values $\left({ }^{*} p<0.5\right.$, ${ }^{* *} p<0.01,{ }^{* * *} p<0.001$, n.s. non-significant) were estimated from non-parametric multiple pairwise comparison Jonckh eere-Terpstra test $\left(\mathrm{T}_{\mathrm{JT}}\right)$.

\section{Discussion}

In this work, we analyzed the CS-glycosaminoglycome from the serum of primary epithelial ovarian cancer patients and compared it with age-matched healthy controls. Seven CS disaccharides and the HA disaccharide could be detected. Regardless of the 
analyzed disease states, CS-OS and CS-4S disaccharides were the major structures present in human serum with a mean relative abundance of around $50-65 \%$ and $33-49 \%$ respectively. The six other disaccharides, namely HA-0S, CS-2S, CS-6S, CS-2S4S, CS-2S6S and CS-4S6S, had low intensities. In addition, no trisulfated CS structures were detected in any of the sera as was observed previously [37]. When compared with mouse serum, human serum contains more non-sulfated CS disaccharides and less disulfated disaccharides [37]. Our data was combined into a ratio named "CS-bio", which showed a statistically significant elevation in FIGO stage I patients $(p<0.001)$ where CA125 was not different. Interestingly, CS-bio did not increase with the disease stage as CA125 did.

As for other types of glycosylation such as IgG asialylation [12], absolute CS amounts present in human plasma were previously shown to increase with age [38]. In this study, we found that the relative amounts of CS disaccharides in human serum were not affected by age. They remained fairly stable with age, which is in line with findings for renal cell carcinoma [39]. The same was observed previously for the chondroitin sulfate sulfotransferases CHST11 and CHST15 in ovarian cancer patients [40]. Carbohydrate sulfotransferase CHST11 was shown to be elevated in ovarian cancer patients in tumor tissues irrespective of the histological subtype, FIGO stage or post-operative residual tumors [40]. CHST11 is responsible for the formation of CS-4S via the transfer of sulfate to the hydroxyl group at position 4 of the GalNAc. This is in line with the increase of CS- 4 S and the decrease of CS-OS that were measured in our study as early as in FIGO stage I patients. Traces of CS-6S observed in serum most likely stems from the degradation of plasma cells [41].

It was previously shown using immunohistochemistry and a specific antibody that CS disulfation, particularly CS-4S6S, is enhanced in ovarian cancer tissues $[17,30,42]$ and in human blood [43]. These observations also correlate with increased mRNA expression of GalNAc4S-6-sulfotransferase, the enzyme that is responsible for the attachment of sulfate groups at positions 4 and 6 in CS polysaccharides [44] and with the increased genomic expression of the CS proteoglycan versican [45]. In addition, versican was previously shown to be increased in malignant stroma surroundings and promoted the growth of several forms of cancer including ovarian cancer [46-48]. Moreover, it correlated with cancer relapse, metastasis and unfavorable prognosis $[49,50]$ but the detailed CS composition of versican has not yet been studied in detail. With the sample preparation protocol that we used, CS-4S6S was observed only as a minor compound both in controls and in EOC patients. It cannot be ruled out that CS-4S6S could be enriched using another protocol whereas CS-OS could be somehow depleted, for instance in an anion-exchange chromatography step.

The modulation of CS disaccharides was also studied previously in the plasma and urine of renal cell carcinoma patients $[39,51,52]$ but not for serum, which may contain a different profile from plasma as clotting factors are not present. The CS profiles obtained for renal cell carcinoma were different from the ones obtained for EOC in this study: CS$6 \mathrm{~S}$ and the ratio CS-6S/CS-4S were increased in renal cancer whereas CS-4S was increased in our study $[39,51,52]$.

One of the proteoglycans involved could be the serine protease inhibitor bikunin, the most abundant proteoglycan present in blood. Synthesized by hepatocytes, the CS moiety of bikunin contains the two motifs CS-0S and CS-4S and is only O-sulfated at the first five GalNAc of the reducing end [53]. Bikunin was previously shown to be overexpressed in the blood and within tumors of ovarian cancer patients [54]. In addition, it was also observed in the secretome of other carcinoma cell lines, such as squamous cell carcinoma, glioma, and rhabdomyosarcoma [55].

\section{Conclusions}

To conclude, we studied for the first time the composition of GAG at the disaccharide level and established a novel serum GAG-based biomarker named CS-bio that was particularly able to differentiate EOC early stages from healthy controls and which outperformed CA125. In future studies, these performances would need to be validated in a larger cohort. 
Supplementary Materials: The following are available online at https:/ / www.mdpi.com/article/ 10.3390/diagnostics11071143/s1, Figure S1: Representative HPLC chromatograms of 2AB-labeled CS-disaccharides isolated from an ovarian cancer patient (upper panel) and a healthy control (lower panel), Figure S2: (a) Mean and 95\% confidence intervals [1] of relative areas of CS disaccharides released from human serum measured by HPLC coupled to fluorescence detection. (b) Enlarged view of the low abundant CS disaccharides. $S$ indicates sulfate and the preceding digit indicates the sulfation position, Figure S3: ROC curves of the disaccharides that were of statistical significance in this study, Figure S4: Association between disaccharide CS-0S (a), CS-2S (b) and CS-4S (c) (Yaxis) and age of the patient cohort (X-axis). Descriptive statistics are in terms of $\mathrm{R}^{2}$ (coefficient of determination), $\mathrm{b}$ (regression $\mathrm{b}$ coefficient) and $p$ ( $p$-values), Table S1: CS-disaccharides were released from a healthy control, labeled with 2-AB and measured by HPLC in triplicate. Mean, standard deviation and coefficient of variation are presented in the Table for each CS disaccharide, Table S2: CS-disaccharides were released from a healthy control in triplicate, labeled with 2-AB and measured by HPLC. Mean, standard deviation and coefficient of variation are presented in the Table for each CS disaccharide.

Author Contributions: Conceptualization, V.B., E.I.B., and J.S.; methodology, software, and validation. K.B. and C.S.; formal analysis, K.B.; investigation, K.B., C.S., and V.B.; resources, E.I.B., J.S., and V.B.; data curation, K.B. and E.I.B.; writing—original draft preparation, K.B. and V.B.; writing-review, editing and visualization, all authors; supervision, project administration and funding acquisition, V.B. All authors have read and agreed to the published version of the manuscript.

Funding: This research was funded by the German Research Foundation through the Collaborative Research Centre 1340 entitled "Matrix-in-Vision".

Institutional Review Board Statement: The Ethics Committee of the Charité-Universitätsmedizin Berlin approved the use of OC samples and controls (EA4/073/06) and of sepsis samples (EA1/285/09).

Informed Consent Statement: Informed consent was obtained from all OC and control subjects involved in the study. Patient consent was waived for sepsis patients because samples were collected as anonymized left-over material from the routine diagnostic laboratories.

Acknowledgments: Axel Teigeler is acknowledged for his technical support.

Conflicts of Interest: The authors declare no conflict of interest.

\section{References}

1. Siegel, R.L.; Miller, K.D.; Jemal, A. Cancer statistics, 2019. CA Cancer J. Clin. 2019, 69, 7-34. [CrossRef] [PubMed]

2. Mathieu, K.B.; Bedi, D.G.; Thrower, S.L.; Qayyum, A.; Bast, R.C., Jr. Screening for ovarian cancer: Imaging challenges and opportunities for improvement. Ultrasound Obstet. Gynecol. 2018, 51, 293-303. [CrossRef] [PubMed]

3. Bowtell, D.D.; Bohm, S.; Ahmed, A.A.; Aspuria, P.J.; Bast, R.C., Jr.; Beral, V.; Berek, J.S.; Birrer, M.J.; Blagden, S.; Bookman, M.A.; et al. Rethinking ovarian cancer II: Reducing mortality from high-grade serous ovarian cancer. Nat. Rev. Cancer 2015, 15, 668-679. [CrossRef]

4. Elias, K.M.; Guo, J.; Bast, R.C., Jr. Early Detection of Ovarian Cancer. Hematol. Oncol. Clin. N. Am. 2018, 32, 903-914. [CrossRef]

5. Heitz, F.; Kommoss, S.; Tourani, R.; Grandelis, A.; Uppendahl, L.; Aliferis, C.; Burges, A.; Wang, C.; Canzler, U.; Wang, J.; et al. Dilution of Molecular-Pathologic Gene Signatures by Medically Associated Factors Might Prevent Prediction of Resection Status After Debulking Surgery in Patients With Advanced Ovarian Cancer. Clin. Cancer Res. 2020, 26, 213-219. [CrossRef] [PubMed]

6. Dochez, V.; Caillon, H.; Vaucel, E.; Dimet, J.; Winer, N.; Ducarme, G. Biomarkers and algorithms for diagnosis of ovarian cancer: CA125, HE4, RMI and ROMA, a review. J. Ovarian Res. 2019, 12, 28. [CrossRef]

7. Van Gorp, T.; Cadron, I.; Despierre, E.; Daemen, A.; Leunen, K.; Amant, F.; Timmerman, D.; De Moor, B.; Vergote, I. HE4 and CA125 as a diagnostic test in ovarian cancer: Prospective validation of the Risk of Ovarian Malignancy Algorithm. Br. J. Cancer 2011, 104, 863-870. [CrossRef]

8. Moss, H.A.; Berchuck, A.; Neely, M.L.; Myers, E.R.; Havrilesky, L.J. Estimating Cost-effectiveness of a Multimodal Ovarian Cancer Screening Program in the United States: Secondary Analysis of the UK Collaborative Trial of Ovarian Cancer Screening (UKCTOCS). JAMA Oncol. 2018, 4, 190-195. [CrossRef]

9. Biskup, K.; Braicu, E.I.; Sehouli, J.; Fotopoulou, C.; Tauber, R.; Berger, M.; Blanchard, V. Serum glycome profiling: A biomarker for diagnosis of ovarian cancer. J. Proteome Res. 2013, 12, 4056-4063. [CrossRef]

10. Dedova, T.; Braicu, E.I.; Sehouli, J.; Blanchard, V. Sialic Acid Linkage Analysis Refines the Diagnosis of Ovarian Cancer. Front. Oncol. 2019, 9, 261. [CrossRef]

11. Peng, W.; Zhao, J.; Dong, X.; Banazadeh, A.; Huang, Y.; Hussien, A.; Mechref, Y. Clinical application of quantitative glycomics. Expert Rev. Proteom. 2018, 15, 1007-1031. [CrossRef] [PubMed] 
12. Wieczorek, M.; Braicu, E.I.; Oliveira-Ferrer, L.; Sehouli, J.; Blanchard, V. Immunoglobulin G Subclass-Specific Glycosylation Changes in Primary Epithelial Ovarian Cancer. Front. Immunol. 2020, 11, 654. [CrossRef]

13. Lindahl, U.; Couchman, J.; Kimata, K.; Esko, J.D. Proteoglycans and Sulfated Glycosaminoglycans. In Essentials of Glycobiology, 3rd ed.; Varki, A., Cummings, R.D., Esko, J.D., Stanley, P., Hart, G.W., Aebi, M., Darvill, A.G., Kinoshita, T., Packer, N.H., Prestegard, J.H., et al., Eds.; Cold Spring Harbor: Long Island, NY, USA, 2015; pp. 207-221. [CrossRef]

14. Basappa; Rangappa, K.S.; Sugahara, K. Roles of glycosaminoglycans and glycanmimetics in tumor progression and metastasis. Glycoconj. J. 2014, 31, 461-467. [CrossRef]

15. Silver, D.J.; Silver, J. Contributions of chondroitin sulfate proteoglycans to neurodevelopment, injury, and cancer. Curr. Opin. Neurobiol. 2014, 27, 171-178. [CrossRef]

16. Afratis, N.; Gialeli, C.; Nikitovic, D.; Tsegenidis, T.; Karousou, E.; Theocharis, A.D.; Pavao, M.S.; Tzanakakis, G.N.; Karamanos, N.K. Glycosaminoglycans: Key players in cancer cell biology and treatment. FEBS J. 2012, 279, 1177-1197. [CrossRef]

17. ten Dam, G.B.; van de Westerlo, E.M.; Purushothaman, A.; Stan, R.V.; Bulten, J.; Sweep, F.C.; Massuger, L.F.; Sugahara, K.; van Kuppevelt, T.H. Antibody GD3G7 selected against embryonic glycosaminoglycans defines chondroitin sulfate-E domains highly up-regulated in ovarian cancer and involved in vascular endothelial growth factor binding. Am. J. Pathol. 2007, 171, 1324-1333. [CrossRef]

18. Hinrichs, U.; Rutteman, G.R.; Nederbragt, H. Stromal accumulation of chondroitin sulphate in mammary tumours of dogs. Br. J. Cancer 1999, 80, 1359-1365. [CrossRef] [PubMed]

19. Suhovskih, A.V.; Aidagulova, S.V.; Kashuba, V.I.; Grigorieva, E.V. Proteoglycans as potential microenvironmental biomarkers for colon cancer. Cell Tissue Res. 2015, 361, 833-844. [CrossRef]

20. Lv, H.; Yu, G.; Sun, L.; Zhang, Z.; Zhao, X.; Chai, W. Elevate level of glycosaminoglycans and altered sulfation pattern of chondroitin sulfate are associated with differentiation status and histological type of human primary hepatic carcinoma. Oncology 2007, 72, 347-356. [CrossRef]

21. Ucakturk, E.; Akman, O.; Sun, X.; Baydar, D.E.; Dolgun, A.; Zhang, F.; Linhardt, R.J. Changes in composition and sulfation patterns of glycoaminoglycans in renal cell carcinoma. Glycoconj. J. 2016, 33, 103-112. [CrossRef] [PubMed]

22. Sugahara, K.N.; Hirata, T.; Tanaka, T.; Ogino, S.; Takeda, M.; Terasawa, H.; Shimada, I.; Tamura, J.; ten Dam, G.B.; van Kuppevelt, T.H.; et al. Chondroitin sulfate E fragments enhance CD44 cleavage and CD44-dependent motility in tumor cells. Cancer Res. 2008, 68, 7191-7199. [CrossRef]

23. Theocharis, A.D.; Vynios, D.H.; Papageorgakopoulou, N.; Skandalis, S.S.; Theocharis, D.A. Altered content composition and structure of glycosaminoglycans and proteoglycans in gastric carcinoma. Int. J. Biochem. Cell Biol. 2003, 35, 376-390. [CrossRef]

24. Kalathas, D.; Theocharis, D.A.; Bounias, D.; Kyriakopoulou, D.; Papageorgakopoulou, N.; Stavropoulos, M.S.; Vynios, D.H. Chondroitin synthases I, II, III and chondroitin sulfate glucuronyltransferase expression in colorectal cancer. Mol. Med. Rep. 2011, 4, 363-368. [CrossRef] [PubMed]

25. Kalathas, D.; Triantaphyllidou, I.E.; Mastronikolis, N.S.; Goumas, P.D.; Papadas, T.A.; Tsiropoulos, G.; Vynios, D.H. The chondroitin/dermatan sulfate synthesizing and modifying enzymes in laryngeal cancer: Expressional and epigenetic studies. Head Neck Oncol. 2010, 2, 27. [CrossRef] [PubMed]

26. Yin, L. Chondroitin synthase 1 is a key molecule in myeloma cell-osteoclast interactions. J. Biol. Chem. 2005, 280, 15666-15672. [CrossRef]

27. Zeng, L.; Qian, J.; Luo, X.; Zhou, A.; Zhang, Z.; Fang, Q. CHSY1 promoted proliferation and suppressed apoptosis in colorectal cancer through regulation of the NFkappaB and/or caspase-3/7 signaling pathway. Oncol. Lett. 2018, 16, 6140-6146. [CrossRef] [PubMed]

28. Hayes, A.; Sugahara, K.; Farrugia, B.; Whitelock, J.M.; Caterson, B.; Melrose, J. Biodiversity of CS-proteoglycan sulphation motifs: Chemical messenger recognition modules with roles in information transfer, control of cellular behaviour and tissue morphogenesis. Biochem. J. 2018, 475, 587-620. [CrossRef]

29. Garcia-Suarez, O.; Garcia, B.; Fernandez-Vega, I.; Astudillo, A.; Quiros, L.M. Neuroendocrine tumors show altered expression of chondroitin sulfate, glypican 1, glypican 5, and syndecan 2 depending on their differentiation grade. Front. Oncol. $2014,4,15$. [CrossRef]

30. Vallen, M.J.; Massuger, L.F.; ten Dam, G.B.; Bulten, J.; van Kuppevelt, T.H. Highly sulfated chondroitin sulfates, a novel class of prognostic biomarkers in ovarian cancer tissue. Gynecol. Oncol. 2012, 127, 202-209. [CrossRef] [PubMed]

31. Fotopoulou, C.; Richter, R.; Braicu, E.I.; Schmidt, S.C.; Lichtenegger, W.; Sehouli, J. Can complete tumor resection be predicted in advanced primary epithelial ovarian cancer? A systematic evaluation of 360 consecutive patients. Eur. J. Surg. Oncol. J. Eur. Soc. Surg. Oncol. Br. Assoc. Surg. Oncol. 2010, 36, 1202-1210. [CrossRef] [PubMed]

32. Fotopoulou, C.; Schumacher, G.; Schefold, J.C.; Denkert, C.; Lichtenegger, W.; Sehouli, J. Systematic evaluation of the intraoperative tumor pattern in patients with borderline tumor of the ovary. Int. J. Gynecol. Cancer Off. J. Int. Gynecol. Cancer Soc. 2009, 19, 1550-1555. [CrossRef] [PubMed]

33. Sehouli, J.; Konsgen, D.; Mustea, A.; Oskay-Ozcelik, G.; Katsares, I.; Weidemann, H.; Lichtenegger, W. “IMO”-intraoperative mapping of ovarian cancer. Zent. Gynakol. 2003, 125, 129-135. [CrossRef]

34. Sehouli, J.; Richter, R.; Braicu, E.I.; Buhling, K.J.; Bahra, M.; Neuhaus, P.; Lichtenegger, W.; Fotopoulou, C. Role of secondary cytoreductive surgery in ovarian cancer relapse: Who will benefit? A systematic analysis of 240 consecutive patients. J. Surg. Oncol. 2010, 102, 656-662. [CrossRef] 
35. Sehouli, J.; Savvatis, K.; Braicu, E.I.; Schmidt, S.C.; Lichtenegger, W.; Fotopoulou, C. Primary versus interval debulking surgery in advanced ovarian cancer: Results from a systematic single-center analysis. Int. J. Gynecol. Cancer Off. J. Int. Gynecol. Cancer Soc. 2010, 20, 1331-1340. [CrossRef]

36. Koschack, J. Standardabweichung und Standardfehler: Der kleine, aber feine Unterschied. Z. Allg. 2008, 84, 258-260. [CrossRef]

37. Yoshida, Y.; Furukawa, J.I.; Naito, S.; Higashino, K.; Numata, Y.; Shinohara, Y. Quantitative analysis of total serum glycome in human and mouse. Proteomics 2016, 16, 2747-2758. [CrossRef] [PubMed]

38. Volpi, N.; Maccari, F. Chondroitin sulfate in normal human plasma is modified depending on the age. Its evaluation in patients with pseudoxanthoma elasticum. Clin. Chim. Acta 2006, 370, 196-200. [CrossRef]

39. Gatto, F.; Blum, K.A.; Hosseini, S.S.; Ghanaat, M.; Kashan, M.; Maccari, F.; Galeotti, F.; Hsieh, J.J.; Volpi, N.; Hakimi, A.A.; et al. Plasma Glycosaminoglycans as Diagnostic and Prognostic Biomarkers in Surgically Treated Renal Cell Carcinoma. Eur. Urol. Oncol. 2018, 1, 364-377. [CrossRef]

40. Oliveira-Ferrer, L.; Hessling, A.; Trillsch, F.; Mahner, S.; Milde-Langosch, K. Prognostic impact of chondroitin-4-sulfotransferase CHST11 in ovarian cancer. Tumour Biol. 2015, 36, 9023-9030. [CrossRef]

41. Mantovani, V.; Galeotti, F.; Maccari, F.; Volpi, N. Analytical Methods for Assessing Chondroitin Sulfate in Human Plasma. J. AOAC Int. 2016, 99, 333-341. [CrossRef]

42. van der Steen, S.C.; van Tilborg, A.A.; Vallen, M.J.; Bulten, J.; van Kuppevelt, T.H.; Massuger, L.F. Prognostic significance of highly sulfated chondroitin sulfates in ovarian cancer defined by the single chain antibody GD3A11. Gynecol. Oncol. 2016, 140, 527-536. [CrossRef] [PubMed]

43. Pothacharoen, P.; Siriaunkgul, S.; Ong-Chai, S.; Supabandhu, J.; Kumja, P.; Wanaphirak, C.; Sugahara, K.; Hardingham, T.; Kongtawelert, P. Raised serum chondroitin sulfate epitope level in ovarian epithelial cancer. J. Biochem. 2006, 140, 517-524. [CrossRef]

44. Ito, Y.; Watanabe, M.; Nishizawa, T.; Omachi, T.; Kobayashi, T.; Kasama, S.; Habuchi, O.; Nakayama, J. The utility of formalin-fixed and paraffin-embedded tissue blocks for quantitative analysis of N-acetylgalactosamine 4-sulfate 6-O-sulfotransferase mRNA expressed by colorectal cancer cells. Acta Histochem. Cytochem. 2007, 40, 53-59. [CrossRef] [PubMed]

45. Kulbe, H.; Otto, R.; Darb-Esfahani, S.; Lammert, H.; Abobaker, S.; Welsch, G.; Chekerov, R.; Schafer, R.; Dragun, D.; Hummel, M.; et al. Discovery and Validation of Novel Biomarkers for Detection of Epithelial Ovarian Cancer. Cells 2019, 8, 713. [CrossRef] [PubMed]

46. Voutilainen, K.; Anttila, M.; Sillanpaa, S.; Tammi, R.; Tammi, M.; Saarikoski, S.; Kosma, V.M. Versican in epithelial ovarian cancer: Relation to hyaluronan, clinicopathologic factors and prognosis. Int. J. Cancer 2003, 107, 359-364. [CrossRef]

47. Ricciardelli, C.; Brooks, J.H.; Suwiwat, S.; Sakko, A.J.; Mayne, K.; Raymond, W.A.; Seshadri, R.; LeBaron, R.G.; Horsfall, D.J. Regulation of stromal versican expression by breast cancer cells and importance to relapse-free survival in patients with node-negative primary breast cancer. Clin. Cancer Res. 2002, 8, 1054-1060.

48. Sakko, A.J.; Ricciardelli, C.; Mayne, K.; Tilley, W.D.; Lebaron, R.G.; Horsfall, D.J. Versican accumulation in human prostatic fibroblast cultures is enhanced by prostate cancer cell-derived transforming growth factor beta1. Cancer Res. 2001, 61, 926-930.

49. Lancaster, J.M.; Dressman, H.K.; Clarke, J.P.; Sayer, R.A.; Martino, M.A.; Cragun, J.M.; Henriott, A.H.; Gray, J.; Sutphen, R.; Elahi, A.; et al. Identification of genes associated with ovarian cancer metastasis using microarray expression analysis. Int. J. Gynecol. Cancer Off. J. Int. Gynecol. Cancer Soc. 2006, 16, 1733-1745. [CrossRef]

50. Ghosh, S.; Albitar, L.; LeBaron, R.; Welch, W.R.; Samimi, G.; Birrer, M.J.; Berkowitz, R.S.; Mok, S.C. Up-regulation of stromal versican expression in advanced stage serous ovarian cancer. Gynecol. Oncol. 2010, 119, 114-120. [CrossRef]

51. Gatto, F.; Maruzzo, M.; Magro, C.; Basso, U.; Nielsen, J. Prognostic Value of Plasma and Urine Glycosaminoglycan Scores in Clear Cell Renal Cell Carcinoma. Front. Oncol. 2016, 6, 253. [CrossRef]

52. Gatto, F.; Volpi, N.; Nilsson, H.; Nookaew, I.; Maruzzo, M.; Roma, A.; Johansson, M.E.; Stierner, U.; Lundstam, S.; Basso, U.; et al. Glycosaminoglycan Profiling in Patients' Plasma and Urine Predicts the Occurrence of Metastatic Clear Cell Renal Cell Carcinoma. Cell Rep. 2016, 15, 1822-1836. [CrossRef]

53. Yamada, S.; Oyama, M.; Kinugasa, H.; Nakagawa, T.; Kawasaki, T.; Nagasawa, S.; Khoo, K.H.; Morris, H.R.; Dell, A.; Sugahara, K. The sulphated carbohydrate-protein linkage region isolated from chondroitin 4-sulphate chains of inter-alpha-trypsin inhibitor in human plasma. Glycobiology 1995, 5, 335-341. [CrossRef] [PubMed]

54. Matsuzaki, H.; Kobayashi, H.; Yagyu, T.; Wakahara, K.; Kondo, T.; Kurita, N.; Sekino, H.; Inagaki, K.; Suzuki, M.; Kanayama, N.; et al. Plasma bikunin as a favorable prognostic factor in ovarian cancer. J. Clin. Oncol. Off. J. Am. Soc. Clin. Oncol. 2005, 23, 1463-1472. [CrossRef] [PubMed]

55. Hochstrasser, K.; Reisinger, P.W.; Albrecht, G.J.; Wustrow, T.P. Protease inhibitors as tumor-associated growth factors. Laryngorhinootologie 1989, 68, 51-56. [CrossRef] [PubMed] 